\title{
PRESENTACIÓN
}

\section{CAMBIO TECNOLÓGICO, EXIGENCIAS DE ACCIÓN Y PENSAMIENTO COLABORATIVO}

Technology change, needs for action, and collaborative thought

Actualmente se reconoce que el «saber hacer» es valioso para las empresas y los ciudadanos. El conocimiento es un elemento que ha sido estrechamente ligado a la competitividad; por ello, la tecnología ocupa hoy un lugar importante en la vida cotidiana de las personas. En las empresas, la gestión de la tecnología y la vinculación con universidades, gobiernos y centros de investigación está ligada con el «saber hacer» y más allá de este, con el «saber ser». Este último implica exigencias de acción ciudadana y se objetiva en lograr acciones sustentables y descentralizar procesos para reducir costos. Todo esto permeado por un pensamiento colaborativo que, en los mercados, obliga tanto a profesionistas como a empresarios a tener una capacidad de respuesta rápida ante las exigencias del mercado.

Los cambios cotidianos derivados de las revoluciones tecnológicas, nos obligan a desarrollar estrategias personales, de negocios y de gobierno. En el ámbito profesional lo más importante es brindar una educación de calidad, la cual permita desarrollar habilidades en los estudiantes que les permita satisfacer la demanda de los recursos humanos requeridos por las empresas. Por lo anterior, los programas educativos son constantemente examinados por las certificadoras con la finalidad de asegurar la calidad de la educación que se ofrece.

Los artículos que se presentan en este número nos ofrecen una visión general sobre algunos de los temas que hoy en día son relevantes: el cambio tecnológico, la vinculación entre Gobierno, empresa y universidad, la sustentabilidad y las alternativas de negocios en ramas que pueden tener un mayor desarrollo, así como la necesidad de un nuevo enfoque en la gestión. El texto de la Dra. Alina Bustamante, analiza la oferta universitaria de una de las carreras de pregrado con mayor antigüedad, la Contabilidad. Como cualquier disciplina ha cambiado de acuerdo con las necesidades $y / 0$ exigencias de las organizaciones, siendo hoy concebida como Contabilidad de Gestión, la cual va más allá de la mera contabilidad, implicando la toma de decisiones, considerando información tanto financiera como no financiera relacionada con la organización. El estudio se realiza en tres países: Colombia, Brasil y España.

La autora expone que a nivel de pregrado se cuenta con una formación integral en los tres países; sin embargo, se exhiben coincidencias y diferencias entre estos, presentando, por ejemplo, como debilidad general, la baja promoción a la investigación, principalmente en Colombia, ya que a esta fecha no se cuenta con ningún programa de doctorado que permita estimular la actividad de investigación en esa disciplina.

Por otro lado, Bustamante señala la importancia de reforzar las áreas con un enfoque de gestión de la tecnología, ya que a través de los sistemas de información se obtiene información relevante de las empresas, que es necesario sea bien interpretada para una buena toma de decisiones.

La gestión del conocimiento es indispensable para el avance de cualquier sector; en ese sentido, De la torre, Ramos y González abordan la industria aeroespacial en México.

En el entendido de que la socialización e interiorización del conocimiento versus la 
información son un reto en cualquier nivel empresarial, los hallazgos en la investigación presentada son muy reveladores, pues identifican claramente el panorama de la empresa caso de estudio. Se muestran claras fortalezas en la preparación y especialización que tiene el recurso humano; además, la empresa tiene un alto nivel de involucramiento en su personal, pues son los altos mandos versus los niveles directivos quienes inicialmente analizan la información, estos se encargan de difundirla entre todo su personal, lo que garantiza una mayor participación además de contar con planes de motivación en todos los niveles.

Sin embargo, también se encontraron ciertas problemáticas que no habían sido detectadas; una de ellas es que no se dispone de procedimientos formales que aseguren la transmisión de información, por lo que fácilmente puede creerse que la información fluye, aunque la percepción de los trabajadores a nivel operativo es la contraria. Por último, los autores evidencian como factor clave las tecnologías de información y comunicación en el proceso de gestión del conocimiento.

En cuestión de competitividad, la inteligencia que se desarrolla a nivel empresarial o de Gobierno para establecer estrategias que potencialicen las fortalezas específicas de una organización son sinónimos de éxito.

Por un lado, Nava y Escamilla exponen claramente que no toda la innovación que se presenta en países en desarrollo, como México, se absorbe de la misma manera que en países desarrollados, a pesar de lo innovador que sea el proceso o herramienta tecnológica; es por ello que se requiere de herramientas integrales que estimen el comportamiento de la demanda del producto.

En el ámbito de Gobierno, Mejía presenta una investigación realizada en Guanajuato, México para establecer la factibilidad de un desarrollo turístico sustentable. Sus aportaciones contribuyen a un diagnóstico favorable del lugar, principalmente originan una posibilidad turística para el Estado, ya que no existe un plan de desarrollo turístico establecido. Lo anterior, apoya indudablemente al Estado mismo para tener una futura planeación que favorezca tanto a pobladores como empresarios de la zona.

Continuando con la importancia de la toma de decisiones gubernamentales, Asela realiza una crítica con base en cálculos financieros de la situación fiscal del Departamento de Santander en Colombia, que le permiten identificar problemas estructurales que a largo plazo puede poner en riesgo las finanzas públicas del Departamento.

Ortiz y Caicedo, por su parte, presentan un estudio de la competitividad en empresas de economía solidaria del sector agropecuario, tema indudablemente actual que exhibe una visión fuera de lo tradicional en los negocios, con un enfoque comunitario y no individual. Dentro de la caracterización que los autores realizan se resalta que las empresas son pequeñas y medianas, y es por esa razón que no se tienen procedimientos definidos ni estructurados por lo que se utiliza más la experiencia en toma de decisiones de mercadeo y se tiene baja adopción de nuevas tecnologías debido a la alta resistencia al cambio.

Velázquez, Valencia y Peña destacan en su artículo, la importancia de la vinculación de las universidades con la empresa en el modelo de la triple hélice, y cómo a través de esta se promueve en las empresas la innovación en sus procesos. En el caso de estudio que presentan se expone el escalamiento tecnológico de un proceso de producción y empaquetado en una empresa Pyme, revelando tanto mejoras en el proceso, como mejoras financieras que se comprueban con una proyección financiera. Es necesario resaltar cómo el trabajo conjunto entre universidad, empresa y Gobierno permite a las Pyme acceder a apoyos con los que asimilan la tecnología, permitiéndoles obtener beneficios que los hacen competitivos en los mercados. 
Es inevitable hacer una reflexión sobre cómo se dirigen hoy en día las universidades y empresas y Gobierno; qué se está dejando de hacer, qué se hace mal y qué se puede hacer diferente para mejorar y obtener un beneficio real para la mayor población. Hoy en día se habla de la inteligencia emocional, inteligencia de negocio, destino turístico inteligente, sustentabilidad, sociedad del conocimiento, gestión del conocimiento y economía solidaria, entre otros conceptos; sin embargo, todo lo anterior implica un desapego al conocimiento, al beneficio propio, un cuidado colectivo de las cosas, y muchos países tienen varios obstáculos que vencer para pensar que se puede cambiar de paradigma. Es necesario seguir difundiendo resultados de investigaciones con rigor científico que muestren los éxitos y fracasos de estrategias empresariales o gubernamentales, que permitan ir construyendo con bases sólidas un cambio real en nuestra sociedad.

«El sistema actual está dominado por otras tres palabras mágicas: productividad, competitividad e innovación, que deberían ser sustituidas por repartición cooperación y recreación». José Luis Sampedro.

Dra. Ilia Violeta Cázares-Garrido Universidad Autónoma de Querétaro Querétaro, México

Dra. Alejandra Elizabeth Urbiola-Solís Universidad Autónoma de Querétaro Querétaro, México 